J. Dairy Sci. 92:3185-3193

doi:10.3168/jds.2008-1905

(C) American Dairy Science Association, 2009.

\title{
Binding of different forms of lipopolysaccharide and gene expression in bovine blood neutrophils
}

\author{
M. Worku ${ }^{1}$ and A. Morris \\ Department of Animal Sciences, North Carolina Agricultural and Technical State University, B. C. Webb Hall, 1601 East Market Street, \\ Greensboro 27411
}

\begin{abstract}
The objective of this study was to evaluate the effect of smooth (S) and rough (R) forms of lipopolysaccharide (LPS) on gene expression in bovine blood neutrophils. Isolated neutrophils $\left(10^{7}\right.$ cells $\left./ \mathrm{mL}\right)$ were treated with Escherichia coli LPS serotype O111:B4 $(\mathrm{S}+\mathrm{R})$ and R forms (Ra, Rd, or Rc). Flow cytometry was used to assess surface expression of toll-like receptor 4 (TLR4). Specific primers for IL- 8 , tumor necrosis factor- $\alpha$ (TNF- $\alpha$ ), IL-1 $\beta$, cluster of differentiation antigen 14 (CD14), and natural resistance associated macrophage protein 1 (Nramp1) were used to assess transcription. Secretion of IL- 8 , TNF- $\alpha$, or IL-1 $\beta$ was determined using ELISA kits. Both $\mathrm{S}$ and $\mathrm{R}$ forms of LPS bound to neutrophils. Exposure induced increased surface expression of TLR-4. No TLR-4 or CD14 mRNA was detected but transcripts for IL- 8 , TNF- $\alpha$, IL- $1 \beta$, and Nramp1 were detected. Secretion of IL- 8 and TNF- $\alpha$ but not IL-1 $\beta$ was observed following treatment with $\mathrm{R}$ forms of LPS. The longest $\mathrm{R}$ form tested (Ra) increased RNA purity and IL-8 and TNF- $\alpha$ secretion in bovine neutrophils. The Rd form increased TLR-4 expression and reduced IL- 8 and TNF- $\alpha$ secretion. Exposure to LPS induced increased cell surface expression of TLR-4 and enhanced expression of IL-8 genes. Enhanced TLR4 activity by LPS was not dependent on transcriptional activation. Recruitment of TLR- 4 to the cell membrane may account for increased cell surface expression. A CD14-independent, TLR-4-dependent pathway may be important in the response to different forms of LPS by bovine neutrophils.
\end{abstract}

Key words: lipopolysaccharide, neutrophil, cytokine, gene

\section{INTRODUCTION}

Mastitis is an inflammation that results from infection and subsequent multiplication of pathogenic micro-

Received November 17, 2008.

Accepted March 22, 2009.

${ }^{1}$ Corresponding author: worku@ncat.edu organisms in the mammary gland (National Mastitis Council, 1996). Environmental bacteria such as Escherichia coli, Bacillus spp., and Streptococcus spp. are the most common causes of clinical mastitis in dairy cows (Bannerman et al., 2004). Infection of dairy cows with diverse forms of $E$. coli can be fatal (Burvenich et al., 2003). Studies on virulent forms of $E$. coli infections causing clinical mastitis have been conducted (Wenz et al., 2006).

Lipopolysaccharides found on the outer membrane of E. coli are responsible for the pathogenicity and inflammatory reactions associated with mastitis (Burvenich et al., 2003). Lipopolysaccharide has a hydrophilic O-polysaccharide moiety, a core oligosaccharide, and a hydrophobic lipid A domain in the "smooth" (S) form chemotype. Virulence may be attributed to antigenic variation due to differences in the LPS side chain. Loss of the O-polysaccharide region results in LPS mutants described as "rough" (R) form chemotype of LPS (Ruchaud-Sparagano et al., 1998). The degree of completion of the core oligosaccharide produces different $\mathrm{R}$ forms, such as Ra, Rc, Rd1, Rd2, and Re (Galanos et al., 1979). The $\mathrm{R}$ form of LPS has been shown to elicit a more endotoxic response compared with the $\mathrm{S}$ form of LPS (Huber et al., 2006).

The cells involved with the innate immune response such as neutrophils, macrophages and B cells have specific toll-like receptors (TLR), which recognize specific pathogen-associated molecular patterns such as LPS (Burvenich et al., 2003; Bannerman et al., 2004). The recognition of LPS by TLR-4 is facilitated by the accessory molecules LPS-binding protein $(\mathbf{L B P})$ and cluster of differentiation antigen 14 (CD14) (Paape et al., 1996; Sohn et al., 2007; Ibeagha-Awemu et al., 2008). The interaction of E. coli LPS and LBP with CD14 on cells in the innate immune system leads to the formation and release of endogenous mediators initiating inflammatory and immune responses essential for an antibacterial defense (Guha and Mackman, 2001; Sohn et al., 2007). However, CD14-independent activation has also been reported (Zhang et al., 2000). In bovine leukocytes, TLR-4 was sufficient to promote binding of high concentrations of LPS. However, both bovine 
TLR-4 and the accessory protein MD-2 were required for activation of cytokine genes by LPS (Sauter et al., 2007).

In response to infection in the mammary gland, blood neutrophils bind to the endothelium, migrate through the epithelial and subepithelial matrix, and then localize at the site of infection or in the milk produced in the gland. Proinflammatory cytokines in bovine neutrophils that mediate the localized and systemic response to LPS include IL-1 $\beta$, IL-8, and TNF- $\alpha$ (Shuster et al., 1993; Sohn et al., 2008).

In porcine leukocytes, the LPS-induced expression of natural resistance associated macrophage protein 1 (Nramp1), a highly conserved, critical protein in innate immunity, is time and dose dependent, and is mediated primarily through CD14 (Zhang et al., 2000). Furthermore, induction of Nramp1 in response to LPS, TNF- $\alpha$, and IL- $1 \beta$ involves mitogen-activated protein kinases. Human Nramp1 expression is specific to the myeloid lineage and is acquired during the maturation of neutrophils and monocytes (Govoni and Gros, 1998). Expression of Nramp1 in bovine neutrophils has not been reported. However, exposure to LPS results in induction of Nramp1 in bovine monocytes and is associated with resistance to Staphylococcus aureus mastitis (Joo et al., 2003).

Structural changes in LPS may have important implications for gene expression and the severity of the inflammatory response in bovine mastitis. An involvement of the O-polysaccharide region of LPS in activation of human neutrophils has been observed (RuchaudSparagano et al., 1998). Studies revealing the role of different $\mathrm{R}$ forms of LPS have become more significant given that studies of LPS in mice have shown that $\mathrm{S}$ forms of LPS, which had been previously considered as the classical active form of LPS responsible for endotoxic responses in animals, have a much lower spectrum of activity in cells expressing TLR-4 compared with R forms of LPS (Huber et al., 2006).

Because of the growing importance in understanding how the cells of the innate immune response such as neutrophils are able to recognize and neutralize adverse forms of LPS (R forms) (De Schepper et al., 2008), the main objective of this study was to investigate the effects of structurally different LPS types on gene expression and cytokine production in bovine blood neutrophils.

\section{MATERIALS AND METHODS}

\section{Animals and Blood Sampling}

Three clinically healthy, primiparous, Holstein-Friesian cows in mid-late lactation were randomly picked from the North Carolina Agricultural and Technical State University dairy farm. The protocol was approved by the university animal care and use committee. The cows were clinically free of mastitis and not under any medical or feeding treatment during the period of this study. Fifteen milliliters of blood was collected from the jugular vein of the cows and placed into vacutainer tubes containing anticoagulant.

\section{Isolation of Neutrophils from Blood}

Neutrophils were isolated from blood samples by differential centrifugation and hypotonic lysis of red blood cells using the modified Carlson and Kaneko method (Carlson and Kaneko, 1973). Water used contained less than 0.1 endotoxin units $(\mathrm{EU}) / \mathrm{mL}(10 \mathrm{pg} / \mathrm{mL})$ of endotoxin as checked by the Toxin Sensor Chromogenic LAL Endotoxin Assay Kit (Genescript, Piscataway, NJ).

\section{Counting, Identification, and Viability of Neutrophils}

The total number of isolated cells was determined on a hemacytometer. Differential cell counts were determined from smears prepared from the cell suspension. The smears were air-dried, fixed, and stained with Sure Stain Wright (Fisher Scientific Company, Pittsburgh, PA). The number of neutrophils was identified based on granularity and staining out of a total of 100 cells. The purity of cells was expressed as a percentage $(>90 \%)$. Neutrophil viability was assessed using the Trypan blue dye (Sigma Chemical Co., St. Louis, MO) exclusion method by counting 100 cells in duplicate and determining the number of cells.

\section{Lipopolysaccharide Sources}

Lipopolysaccharides were purchased from SigmaAldrich (St. Louis, MO). A mixture of $\mathrm{S}$ and $\mathrm{R}$ forms of LPS was found in LPS from E. coli O111:B4 (cat. no. L6893). Rough form LPS of varying polysaccharide chains: Ra (long R LPS), Rc (intermediate R LPS), and Rd (short R LPS; Sigma-Aldrich) were also used.

\section{Treatment of Neutrophils with Different Forms of LPS, and Collection of Supernatants for Secreted Cytokines}

Isolated neutrophils $\left(10^{7}\right.$ cells $\left./ \mathrm{mL}\right)$ in PBS were treated with the Ra, Rc, and Rd forms of LPS and serotype O111:B4 at 2 concentrations, 10 and $100 \mathrm{ng}$, and for 10,15 , or $30 \mathrm{~min}$. The cells were maintained in an incubator at $37^{\circ} \mathrm{C}$ with $85 \%$ humidity and $5 \% \mathrm{CO}_{2}$. At the end of the incubation period, the tubes containing the samples were returned to ice. Neutrophils 
Table 1. Primer sequences and expected size of PCR products for the target genes

\begin{tabular}{llc}
\hline Gene $^{1}$ & Primer sequence $^{2}$ & Length (bp) \\
\hline IL-8 & For: 5'-GGAAAAGTGGGTGCAGAAGGT-3' & 443 \\
& Rev: 5'-GGTGGTTTTTTCTTTTTCATGGA-3' & \\
TNF- $\alpha$ & For: 5'-CGGTGGTGGGACTCGTATG-3' & 352 \\
& Rev: 5'-CTGGTTGTCTTCCAGCTTCACA-3' & \\
IL-1 $\beta$ & For: 5'-GCCTTCAATAACTGTGGAACCAAT-3' & 100 \\
& Rev: 5'-GTATATTTCAGGCTTGGTGAAAGGA-3' & \\
TLR-4 & For: 5'-AACCACCTCTCCACCTTGATACTG-3' & 452 \\
& Rev: 5'-CCAGVVAGACCTTGAATACAGG-3' & \\
CD14 & For: 5'-GACGACGATTTCCGTTGTGT-3' & 600 \\
& Rev: 5'-TGCGTAGCGCTAGATATTGGA-3' & 433 \\
Nramp1 & For: 5'-CATGAAGCCAACTGCCAAGG-3' & \\
& Rev: 5'-GAAGCCTGCAAGATGACCAACA-3' \\
\hline
\end{tabular}

${ }^{1} \mathrm{TNF}-\alpha=$ tumor necrosis factor- $\alpha$; TLR- $4=$ toll-like receptor 4 ; CD14 = cluster of differentiation antigen 14; Nramp1 = natural resistance associated macrophage protein 1.

${ }^{2}$ For $=$ forward; Rev $=$ reverse.

maintained in PBS were used as a control. Treated cells were centrifuged at $500 \times g$ for $5 \mathrm{~min}$ at $4^{\circ} \mathrm{C}$. The supernatants were stored at $-70^{\circ} \mathrm{C}$ before being used for detection of secreted cytokines by ELISA. The supernatants from isolated neutrophils were thawed and used in separate ELISA assays to detect specific cytokines. The concentrations of TNF- $\alpha$, IL- 8 , and IL-1 $\beta$ were determined using ELISA essentially as described by Bannerman et al. (2004).

\section{Isolation of RNA and Reverse Transcription PCR}

The neutrophil pellets were washed by centrifuging at $500 \times g$ for 5 min in PBS. Total RNA was isolated using Tri-reagent (Molecular Research Center Inc., Cincinnati, $\mathrm{OH}$ ). The quality and quantity of the RNA was measured with the 2100 Agilent Bioanalyzer (Agilent Technologies, Santa Clara, CA). The quality of RNA was assessed by examining the rRNA ratio $(28 \mathrm{~S} / 18 \mathrm{~S})$.

Complementary DNA was prepared using the Retroscript kit (Ambion Inc., Austin, TX). Reverse transcription PCR was conducted in a thermocycler (MWG Biotech Inc., High Point, NC) with specific primers for
TLR-4, CD14, and GAPDH as used by Zughaier et al. (2005); and with specific primers for IL-1 $\beta$, IL-8, and TNF- $\alpha$ as used by Coussens et al. (2004). Primers for Nramp1 were as described by Ables et al. (2002). All the primers (Table 1) used in this study were synthesized by MWG Biotech Inc. Comparison to the GAPDH probe was used to assess if differences in expression detected among the various RNA samples were due to differences in loading on the gel. Specific PCR conditions for TNF- $\alpha$, TLR-4, CD14, Nramp1, GAPDH, IL-8, and IL-1 $\beta$ are shown in Table 2.

\section{Detection of TLR-4 Cell Surface Expression by Flow Cytometry}

Neutrophils treated with $100 \mathrm{ng}$ of LPS O111:B4 or $\mathrm{Rd}$ or maintained in PBS for $30 \mathrm{~min}$, were washed by centrifugation at $500 \times g$ and resuspended in $250 \mu \mathrm{L}$ of PBS. Neutrophils $\left(10^{7}\right.$ cells) were then incubated with $3 \mu \mathrm{g}$ of mouse anti human-TLR-4 antibody (Imgenex, San Diego, CA) for 25 min at $4^{\circ} \mathrm{C}$ with periodic mixing. Following incubation, the cells were washed again and resuspended in $250 \mu \mathrm{L}$ of PBS. Then, cells were

Table 2. Polymerase chain reaction conditions for TNF- $\alpha$, TLR4, CD14, GAPDH, and IL-1 $\beta$ genes (30 PCR cycles) and for IL-8 and Nramp1 genes (33 PCR cycles) ${ }^{1}$

\begin{tabular}{|c|c|c|c|c|}
\hline \multirow[b]{2}{*}{ PCR step } & \multicolumn{2}{|c|}{ TNF- $\alpha$, TLR4, CD14, GAPDH, and IL-1 $\beta$} & \multicolumn{2}{|c|}{ IL-8 and Nramp1 } \\
\hline & Temperature $\left({ }^{\circ} \mathrm{C}\right)$ & Time (min) & Temperature $\left({ }^{\circ} \mathrm{C}\right)$ & Time $(\min )$ \\
\hline Preheating & 94 & 5 & 94 & 5 \\
\hline Denaturation & 94 & 0.5 & 94 & 1 \\
\hline Annealing & 56 & 0.5 & 58 & 1 \\
\hline Postheating & 72 & 0.5 & 72 & 1 \\
\hline Elongation & 72 & 5 & 72 & 5 \\
\hline
\end{tabular}

${ }^{1} \mathrm{TNF}-\alpha=$ tumor necrosis factor- $\alpha$; TLR-4 = toll-like receptor 4 ; CD14 = cluster of differentiation 14 ; Nramp1 $=$ natural resistance associated macrophage protein 1 . 

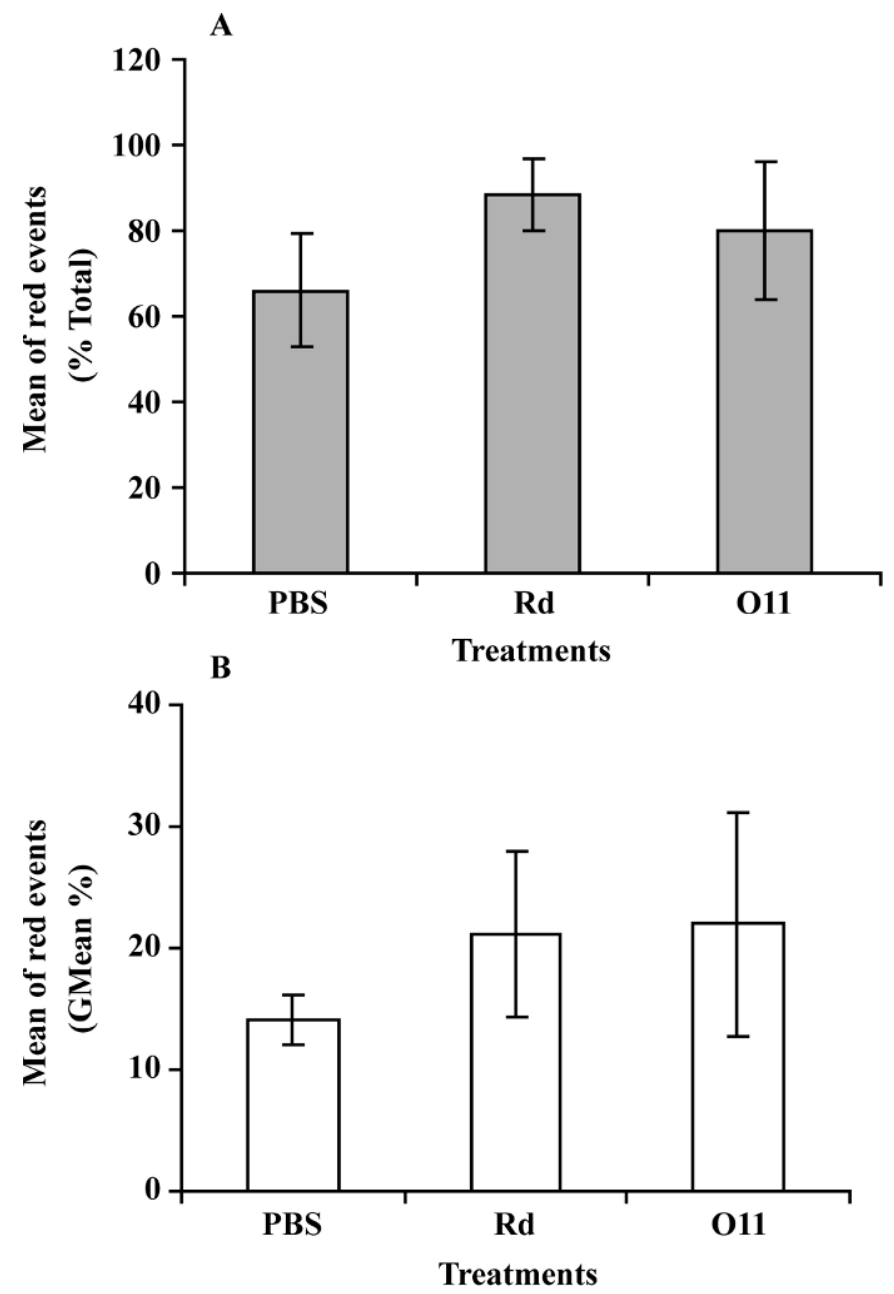

Figure 1. Increased surface expression of toll-like receptor 4 (TLR4) in neutrophils stimulated with the rough form (Rd) and O111:B4 (O11) form of LPS. Peripheral blood neutrophils were incubated with LPS (100 ng of Rd or O111:B4 forms of LPS for $30 \mathrm{~min}$ at $37^{\circ} \mathrm{C}$ ). Cells were stained with antibodies specific to human TLR4 and then with a secondary antibody conjugated to allophycocyanin. A) Binding of anti-TLR4 monoclonal antibody (\% total) was significantly higher in LPS-treated neutrophils compared with cells maintained in PBS $(P<0.05)$; B) The log mean fluorescence intensity (a measure of expression of TLR4) recorded as the geometric mean (GMean \%) was not affected by LPS exposure $(P>0.05)$. Results represent the averages for 3 animals expressed as mean $\pm \mathrm{SE}$.

incubated for $25 \mathrm{~min}$ at $4^{\circ} \mathrm{C}$ with $1 / 100$ diluted allophycocyanin-conjugated goat anti-mouse IgG (Jackson ImmunoResearch Laboratories Inc., Baltimore, PA).

Flow cytometric analysis was conducted using the on-chip antibody staining protocol (Gerd et al., 2002) with the Agilent Cell Checkout Kit (Agilent Technologies). Ten microliters of each cell suspension (treated and control) was loaded into the chip as recommended by the instrument manufacturer (Gerd et al., 2002). Each cell that passed through the detector was counted as an event. Cells were electronically counted using the blue (calcein AM) to red (allophycocyanin) fluorescence protocol. The total number of cells counted, the percentage of cells fluorescing, and the geometric mean (a measure of log mean fluorescence intensity and antibody binding) were recorded.

\section{Statistical Analysis}

Statistical analysis was conducted using SAS software (SAS Institute Inc., Cary, NC). An ANOVA was performed to determine the differences between the treated groups. Furthermore, a Dunnett's $t$-test was also carried out to compare differences between the mean of any individual group and other remaining groups.

\section{RESULTS}

Although no mRNA was detected for TLR-4 or CD14, exposure to LPS induced increased cell surface expression of TLR-4 (Figure 1). The percentage of total neutrophils binding the monoclonal antibody to TLR-4 was increased by treatment with both $\mathrm{S}$ and $\mathrm{R}$ forms of LPS $(P<0.05$; Figure 1A). No significant difference was observed in the level of TLR-4 expression between treatments with $\mathrm{S}$ and $\mathrm{R}$ forms of LPS or the PBStreated control (Figure 1B). Treatment of neutrophils with Ra, Rc, and Rd LPS (10 $\mu \mathrm{L}$ each) for 10 and 30 min had no effect on cell viability $(P>0.05$; Figure 2 ). Results of the Trypan blue dye exclusion method showed that more than $95 \%$ of the cells in each treatment condition remained viable over the study period.

No significant differences were observed in the concentration of RNA isolated following exposure with different forms of LPS $(P>0.05)$. The length of time of exposure to LPS had no effect $(P>0.05)$ on the level of transcription of total RNA in bovine blood neutrophils (Table 3). The concentration of total RNA tended to increase with increased length of time of exposure to LPS. Treatment with the Ra form of LPS resulted in significantly higher purity of total RNA $(P<0.05)$. Only samples with high RNA quality were used for synthesis of cDNA.

The results of induction of mRNA in bovine neutrophils after treatment with $100 \mathrm{ng}$ of $E$. coli O111:B4 ( $\mathrm{S}+\mathrm{R}$ forms) are presented in Figure 3 (panels A to $\mathrm{C}$ ). Gene expression was observed in untreated (PBS control) and O111:B4 LPS treated neutrophils. Transcripts of the genes for IL-8, IL-1 $\beta$, Nramp1, and TNF- $\alpha$ were amplified (Figure 3, panels A to C; Figure 4). Expression of Nramp1 was observed in all samples tested. Comparison with the GAPDH probe showed qualitatively that differences in expression detected among the various RNA samples were not due to differences in loading on the gel (Figure 3D). Qualitative differences 
Table 3. Concentration and purity of RNA after treatment with different rough forms (Ra, Rc, Rd) of LPS for 10 and 30 min ${ }^{1}$

\begin{tabular}{|c|c|c|c|c|}
\hline Treatment & \multicolumn{2}{|c|}{10 min of incubation } & \multicolumn{2}{|c|}{30 min of incubation } \\
\hline Control (PBS) & $37.17 \pm 12.09$ & $0.73 \pm 0.36$ & $48.17 \pm 19.45$ & $0.98 \pm 0.35$ \\
\hline $\mathrm{Rc}$ & $36.17 \pm 9.31$ & $0.82 \pm 0.33^{\mathrm{a}}$ & $42.00 \pm 15.32$ & $1.17 \pm 0.35$ \\
\hline $\mathrm{Rd}$ & $20.67 \pm 2.11$ & $0.37 \pm 0.30^{\mathrm{a}}$ & $29.83 \pm 4.89$ & $0.85 \pm 0.28$ \\
\hline
\end{tabular}

${ }^{\mathrm{a}}$ The highest purity of RNA was isolated from cells treated with the Ra form of LPS, $P<0.05$.

${ }^{1}$ Results represent the averages for 3 animals expressed as mean $\pm \mathrm{SE}$.

were observed in effects of the different forms of LPS on gene expression (Figure 4). Treatment of neutrophils with $\mathrm{R}$ forms of LPS induced increased expression of the gene encoding IL-8 (Figure 4A). This increased expression of IL- 8 genes was indicated by a qualitatively higher intensity in staining when cells were treated with $\mathrm{R}$ forms of LPS compared with O111:B4 LPS and PBS treatment. No expression of IL1 $\beta$ was observed following exposure to $\mathrm{S}$ or $\mathrm{R}$ forms of LPS for $30 \mathrm{~min}$. Thus, expression of IL-1 $\beta$ was observed earlier $(15 \mathrm{~min})$ and not detected at $30 \mathrm{~min}$ of exposure to LPS. Low levels of TNF- $\alpha$ transcripts were detected in cells from 1 out of 2 tested cows in response to exposure to different forms of LPS for $30 \mathrm{~min}$ (Figure 4B).

Exposure of bovine neutrophils to $\mathrm{S}$ and $\mathrm{R}$ forms of LPS induced secretion of IL-8 and TNF- $\alpha$ (Figure 5). The highest amount of IL- 8 was secreted in response to the Ra form of LPS. The lowest concentration of secreted IL-8 was observed following treatment with the $\mathrm{Rc}$ form of LPS. The Ra and Rc forms of LPS resulted in the highest $(P>0.05)$ concentrations of se- creted TNF- $\alpha$. The lowest amounts of TNF- $\alpha$ secretion occurred after exposure to Rd and O111:B4 LPS when compared with the controls (PBS treated).

\section{DISCUSSION}

Our findings show that recognition of different forms of LPS by bovine neutrophils results in cellular activation at the level of transcription and translation. Studies have shown that the severity of $E$. coli mastitis depends mainly upon individual characteristics of the cow, indicating that there is a genetic association with the severity of mastitis (Burvenich et al., 2003; De Schepper et al., 2008). In this study, blood was collected from primiparous cows in mid to late lactation. Animal to animal variation was observed in the level of gene expression.

Neutrophil viability was not affected by exposure to different forms of LPS or length of exposure. Endotoxinmediated priming of neutrophils has been demonstrated in vitro and in vivo and is highly relevant to disease

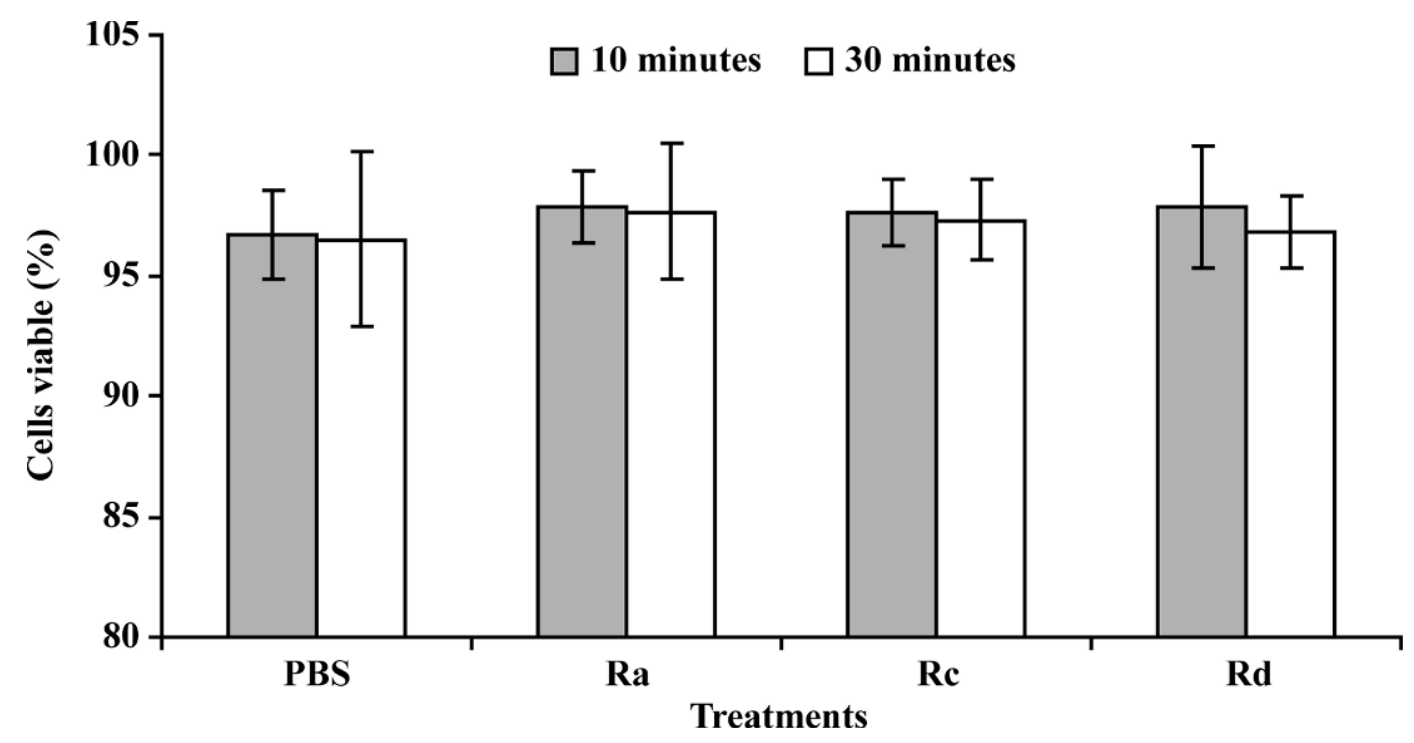

Figure 2. Neutrophil viability after treatment with $10 \mu \mathrm{L}$ of different rough forms of LPS (Ra, Rc, Rd) or PBS (control) for 10 and 30 min. Results represent the averages for 3 animals expressed as mean $\pm \mathrm{SE} ; P>0.05$. 
(A) IL-8

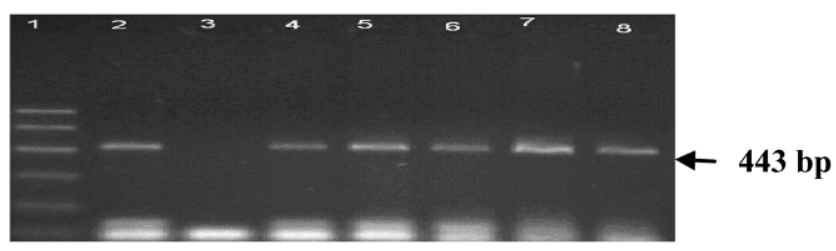

(B) IL-1 $\beta$

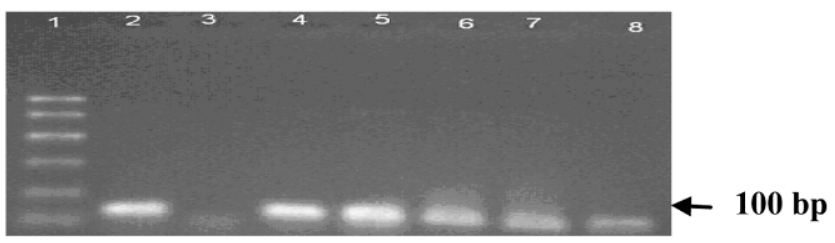

(C) Nramp1

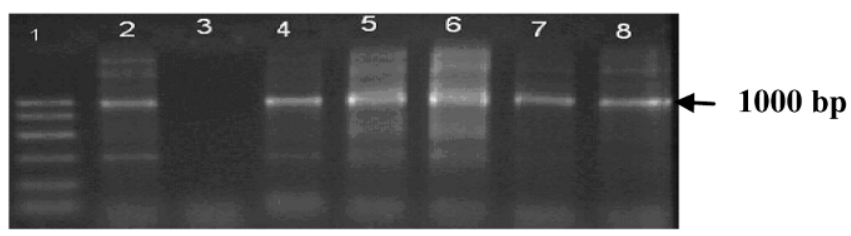

(D) GAPDH

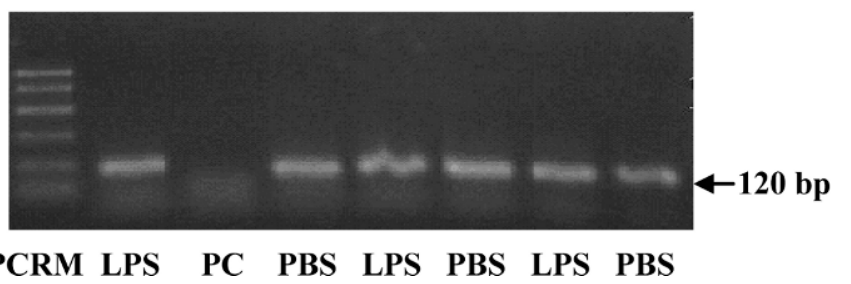

Figure 3. Induction of mRNA in bovine neutrophils ( $\mathrm{n}=3$ cows), after treatment with $100 \mathrm{ng}$ of Escherichia coli O111:B4 (smooth and rough forms) LPS for $15 \mathrm{~min}$ at $37^{\circ} \mathrm{C}$ in the presence of $5 \% \mathrm{CO}_{2}$ and 95\% humidity. A) Expression of IL-8 mRNA (443 bp); B) expression of IL-1 $\beta$ mRNA (100 bp); C) expression of natural resistance associated macrophage protein 1 (Nramp 1) mRNA (1,000 bp); D) expression of GAPDH loading control (120 bp). Lane $1=$ PCR marker (PCRM; $1,000,750,500,300,150$, and $50 \mathrm{bp}$ fragments); lane $2=\mathrm{LPS}$; lane 3 $=$ primer control (PC); lane $4=$ PBS (animal no. 1); lane $5=$ LPS; lane $6=$ PBS; lane $7=$ LPS; and lane $8=$ PBS. Arrows indicate the expected position of $\mathrm{PCR}$ product.

pathogenesis (McClenahan et al., 2000). Studies have shown that in vitro induction of apoptosis of bovine neutrophils is not accelerated during endotoxin-induced mastitis (Van Oostveldt et al., 2002; Sohn et al., 2008), indicating that preapoptotic cells were used in this study.

Neutrophils exposed to different forms of LPS did not express mRNA transcripts for TLR-4 or CD14. Binding of LPS to TLR4 results in transmembrane signaling leading to expression of transcription factors nuclear factor- $\kappa \mathrm{B}$ (Notebaert et al., 2005) and the activated protein 1, mitogen-activated protein kinase (MAPK), and p38 (Monfardini et al., 2002; Parker et al., 2005;
Wenz et al., 2006). Recognition of LPS and subsequent signaling is associated with interaction with CD-14 (Parker et al., 2005). In the present study, binding of LPS occurred in the absence of LBP and the results reflect an LBP-independent mechanism for responding to different forms of LPS. In light of the observed gene expression in the absence of LPB, a TLR-4-dependent pathway may be important in the response to different forms of LPS in activation of bovine neutrophils.

In this study, enhanced TLR-4 expression following exposure to $\mathrm{S}$ and $\mathrm{R}$ forms of LPS in bovine neutrophils was not dependent on transcriptional activation. Neither the type of LPS used nor the length of time of exposure influenced the amount of transcription (Table 3). These results indicate that transcriptional regulation may not play a significant role in cell surface expression of TLR4 on bovine neutrophils in response to different forms of LPS. It has been observed that regulation of the TLR-4 signaling pathway probably occurs only minimally at the transcriptional level and is mainly controlled at the protein level, making it a very fast and dynamic process (De Schepper et al., 2008). Recruitment of TLR4 from an intracellular pool to the bovine neutrophil cell surface may occur in response to increasing concentrations of LPS exposure. The observed response may help in understanding how trafficking of TLR4 to and from the cell membrane is regulated, as discussed by De Schepper et al. (2008).

Exposure to both $\mathrm{S}$ and R forms of LPS differentially affected the expression of mRNA for TNF- $\alpha$, IL-1 $\beta$, and IL-8 compared with PBS controls. Genes encoding IL-1 $\beta$, TNF- $\alpha$, and IL-8 were expressed in O111:B4 LPS samples and PBS-treated samples. The observed pattern of transcription and translation of IL-8 and TNF- $\alpha$ was consistent with previous findings of a dose-dependent increase in the secretion of cytokines such as IL- 8 , IL-1 $\beta$, TNF- $\alpha$, and IFN- $\gamma$ when bovine neutrophils were treated with increasing concentrations of LPS from $0,1,10$, and $100 \mu \mathrm{g} / \mathrm{mL}$ for a period of 18 $\mathrm{h}$ (Paape et al., 2006). However, our finding also indicates that a similar pattern occurs following exposure to much lower concentrations of LPS and in a shorter period.

Bovine neutrophils have a low threshold for the detection of LPS and subsequent cell activation. The PBS used in this study contained less than $0.3 \mathrm{EU} / \mathrm{mL}$ of LPS. Thus, cytokine gene expression in bovine neutrophils was induced even at this very low concentration, as has been observed in other cell types (Bosisio et al., 2002). Furthermore, pre-exposure to LPS is shown to induce reduced sensitivity to subsequent challenge with LPS (Nomura et al., 2000). In the current study, increased surface expression of TLR-4 and IL-8 mRNA and secretion provide evidence that desensitization 
(A) IL-8

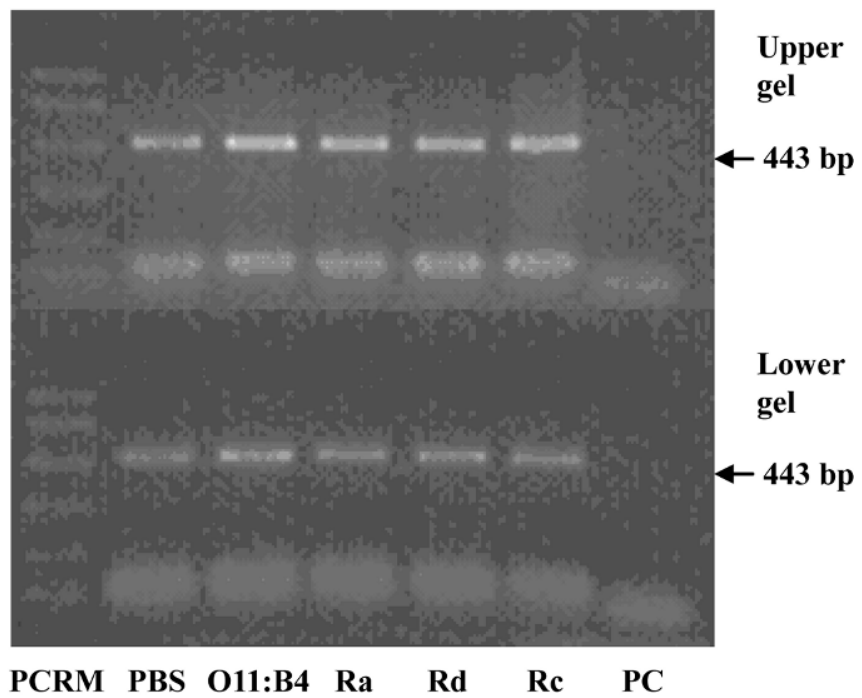

(B) TNF- $\alpha$

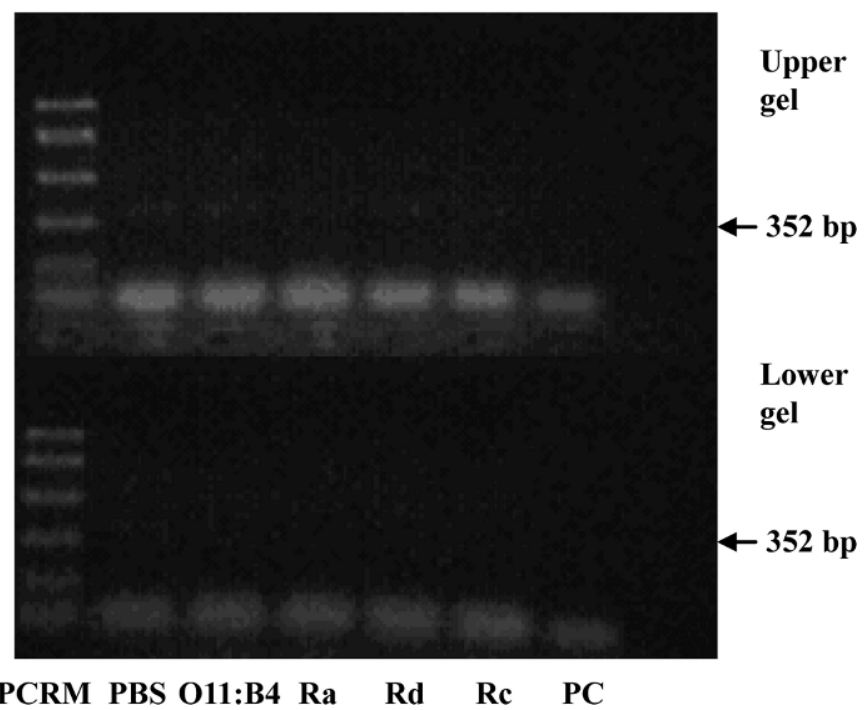

Figure 4. Expression of A) IL- 8 mRNA (443 bp) and B) TNF- $\alpha$ mRNA (352 bp) in bovine neutrophils after induction with $100 \mathrm{ng}$ of different rough (R) forms of LPS (Ra, Rc, and $\mathrm{Rd}$ ) for $30 \mathrm{~min}$ at $37^{\circ} \mathrm{C}$ in the presence of $5 \% \mathrm{CO}_{2}$ and $95 \%$ humidity: Lane $1=\mathrm{PCR}$ marker (PCRM; 1,000, 750, 500, 300, 150, and $50 \mathrm{bp}$ fragments); lane $2=$ PBS; lane $3=$ O11 (Escherichia coli O111:B4 form of LPS); lane $4=$ $\mathrm{Ra}$; lane $5=\mathrm{Rd}$; lane $6=\mathrm{Rc}$; lane $7=$ primer control. Data from 2 animals are presented on the upper and lower gels. Arrows indicate expected positions of PCR products.

did not occur in response to LPS during isolation or incubation. This sensitivity may be of significance for the design of TLR4 agonists for E. coli mastitis (De Schepper et al., 2008).

Increased lengthening of the polysaccharide chain in LPS is associated with variation in cell activation.
A

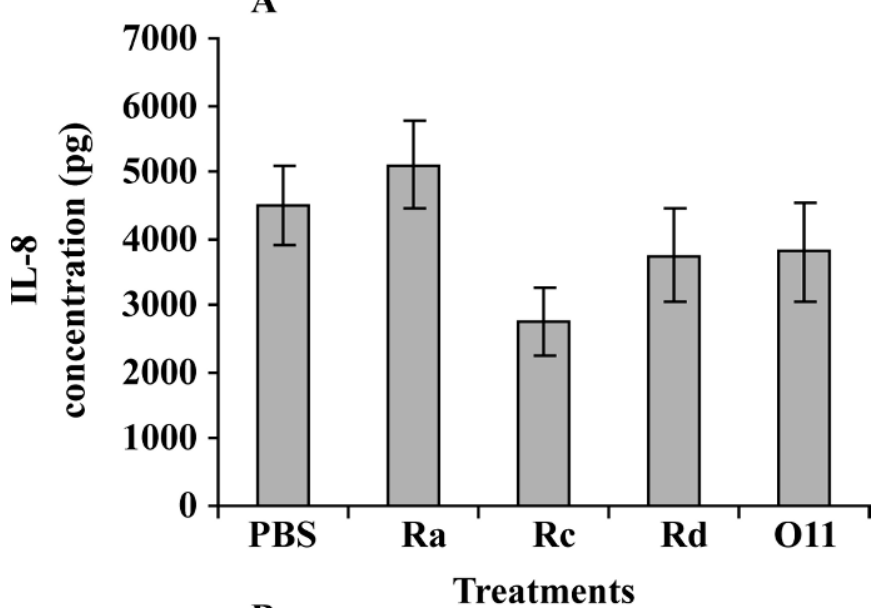

B

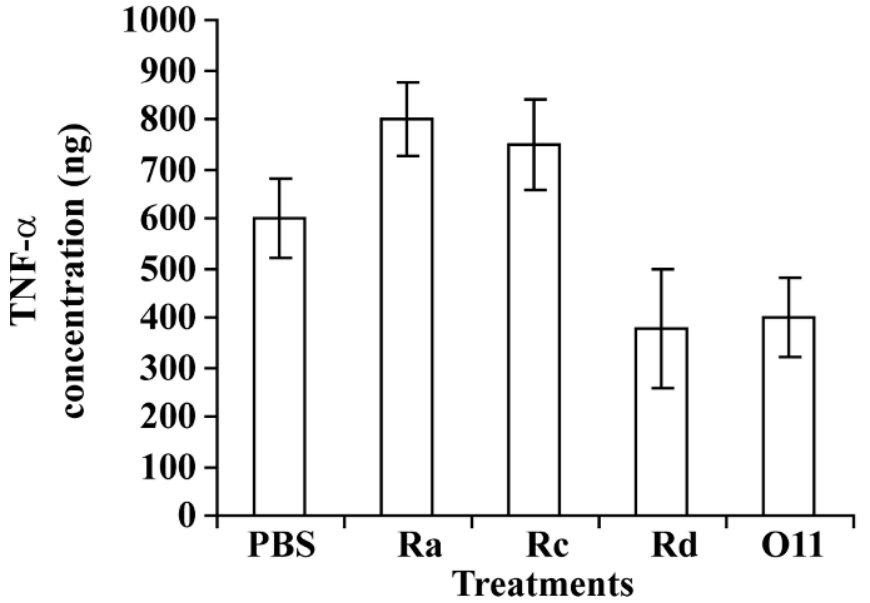

Figure 5. Different rough forms of LPS (Ra, Rc, Rd) and O11 (Escherichia coli O111:B4 form of LPS) stimulated release of IL-8 (panel A) and TNF- $\alpha$ (panel B) cytokine from bovine neutrophils. Neutrophils $\left(10^{7}\right.$ cells) were incubated with different rough forms of LPS $\left(100 \mathrm{ng} / \mathrm{mL}\right.$ at $37^{\circ} \mathrm{C}$ for $30 \mathrm{~min}$ in the presence of $95 \%$ humidity and $5 \% \mathrm{CO}_{2}$ ) or PBS (control). Cytokines were measured in culture supernatants collected at the end of $30 \mathrm{~min}$. Standard curves, generated by using purified IL- 8 ranging from 2,000 to $125 \mathrm{pg} / \mathrm{mL}$ and TNF- $\alpha$ ranging from 200 to $12.5 \mathrm{ng} / \mathrm{mL}$, were used to estimate concentrations of test samples. Results represent the averages for 3 animals expressed as mean $\pm \mathrm{SE} ; P>0.05$.

A direct correlation was observed between the length of the polysaccharide chain and induction of cytokines by human neutrophils (Vinokurov et al., 2006). In this study, the longest $\mathrm{R}$ form tested ( $\mathrm{Ra}$ ) was associated with increased RNA purity and IL- 8 and TNF- $\alpha$ secretion in bovine neutrophils. The shortest $\mathrm{R}$ form tested (Rd) was associated with increased TLR-4 expression and reduced IL- 8 and TNF- $\alpha$ secretion. Treatment with the Rc form of LPS decreased secretion of IL- 8 and increased secretion of TNF- $\alpha$. Vaccination of dairy cows with the E. coli strain J5, a rough (Rc) mutant strain, stimulates the production of antibodies (Dosogne et al., 2002). Our results support the observation that vari- 
able efficacy of this vaccine may be explained by a TLR response (De Schepper et al., 2008) and induction of cytokines IL- 8 and TNF- $\alpha$.

The IL-1 $\beta$ gene was not expressed at $30 \mathrm{~min}$ with $\mathrm{R}$ forms of LPS, but was expressed at $15 \mathrm{~min}$ in the presence of both S and R forms of LPS (O111:B4) and in controls (PBS treated). No secretion of IL-1 $\beta$ was observed. Previous findings have reported secretion of IL-1 $\beta$ by bovine neutrophils treated with LPS at concentrations of 10 or $100 \mu \mathrm{g} / \mathrm{mL}$, but the duration of LPS treatment was $18 \mathrm{~h}$ (Paape et al., 2006). Binding of IL-1 $\beta$ to soluble receptors can result in an underestimation of the amount of IL-1 $\beta$ in a sample (De Jager and Rijkers, 2006).

Studies conducted on human neutrophils have shown that there is a priming effect of LPS on neutrophils at the concentration (100 ng) used for this study. Those studies have shown that when neutrophils are pretreated with concentrations of LPS (10-100 ng) for 60 min and then exposed to subsequent stimuli, there is a dramatic increase in the release of free radicals such as $\mathrm{O}_{2}$ and $\mathrm{H}_{2} \mathrm{O}_{2}$ by neutrophils. In the current study, bovine neutrophils were exposed for only $30 \mathrm{~min}$, which might be insufficient to have a priming effect. Reports also indicate a role for TNF- $\alpha$-induced priming of human neutrophils for a subsequent robust proinflammatory response but there is no reported evidence for IL-1 $\beta$-induced priming of bovine neutrophils (Lewkowicz et al., 2005). This might explain the lack of IL-1 $\beta$ expression at $30 \mathrm{~min}$. Incubation of neutrophils for a longer period might have shown IL-1 $\beta$ production. A synergistic effect of IFN- $\gamma$ and LPS on increased secretion of IL-8, IL-1 $\beta$, and TNF- $\alpha$ has also been reported in human neutrophils (Pearl-Yafe et al., 2007).

To our knowledge, this is the first report of the expression of Nramp1 in bovine neutrophils and its possible role in the response to LPS. In light of Nramp1's wide range of pleiotropic effects including availability of iron (Mulero et al., 2002) and regulation of IL-1 $\beta$ and TNF- $\alpha$ (Zhang et al., 2000), Nramp1 may help limit bacterial growth following infection through activation of MAPK (Lafuse et al., 2002).

\section{CONCLUSIONS}

Low concentrations of structurally different forms of LPS bind to bovine neutrophils and affect gene expression at the level of transcription and translation in the absence of LBP. Surface expression of TLR-4 was not regulated at the level of transcription and might be the result of rapid translocation of proteins from intracellular pools. Increased expression of TLR-4 may be important in LBP and CD14 independent activation of bovine neutrophils contributing to the proinflammatory response. The length of the polysaccharide chain affects the secretion of cytokines in response to LPS. Bovine blood neutrophils expressed Nramp1.These findings will help define the molecular events associated with recognition of LPS and have important implications for understanding the mechanisms underlying regulation of the inflammatory response to LPS in mastitis and may aid in the design of therapeutics.

\section{REFERENCES}

Ables, G. P., M. Nishibori, M. Kanemaki, and T. Watanabe. 2002. Sequence analysis of the Nramp1 genes from different bovine and buffalo breeds. J. Vet. Med. Sci. 64:1081-1083.

Bannerman, D. D., M. J. Paape, W. R. Hare, and J. C. Hope. 2004. Characterization of the bovine innate immune response to intramammary infection with Klebsiella pneumoniae. J. Dairy Sci. 87:2420-2432.

Bosisio, D., N. Polentarutti, M. Sironi, S. Bernasconi, K. Mivake, G. R. Webb, M. U. Martin, A. Mantovani, and M. Muzio. 2002. Stimulation of Toll-like receptor 4 expression in human mononuclear phagocytes by interferon-gamma: A molecular basis for priming and synergism with bacterial lipopolysaccharide. Blood 99:3427-3431.

Burvenich, C., V. Merris Van, J. Mehrzad, A. Diez-Franko, and L. Duchateau. 2003. Severity of E. coli mastitis is mainly determined by cow factors. Vet. Res. 34:521-564.

Carlson, G. P., and J. J. Kaneko. 1973. Isolation of leukocytes from bovine peripheral blood. Proc. Soc. Exp. Biol. Med. 142:853856.

Coussens, P. M., N. Verman, M. A. Coussens, M. D. Elftman, and A. M. McNulty. 2004. Cytokine gene expression in peripheral blood mononuclear cells and tissues of cattle infected with Mycobacterium avium subsp. paratuberculosis: Evidence for an inherent proinflammatory gene expression pattern. Infect. Immun. 72:1409-1422.

De Jager, W., and G. T. Rijkers. 2006. Solid-phase and bead-based cytokine immunoassay: A comparison. Methods 38:294-303.

De Schepper, S., A. De Ketelaere, D. D. Bannerman, M. J. Paape, L. Peelman, and C. Burvenich. 2008. The toll-like receptor-4 (TLR4) pathway and its possible role in the pathogenesis of Escherichia coli mastitis in dairy cattle. Vet. Res. 39:5.

Dosogne, H., E. Meyer, A. Sturk, J. Van Loon, A. M. Massart-Leën, and C. Burvenich. 2002. Effect of enrofloxacin treatment on plasma endotoxin during bovine Escherichia coli mastitis. Inflamm. Res. $51: 201-205$.

Galanos, C., M. A. Freudenberg, O. Luderitz, E. T. Rietschel, and O. Westphal. 1979. Chemical, physicochemical and biological properties of bacterial lipopolysaccharides. Pages 321-332 in Biomedical Applications of the Horseshoe Crab (Limulidae). E. Cohen, ed. A. R. Liss, New York, NY.

Gerd, L., S. Martina, and P. Tobias. 2002. Detecting cell surface proteins with the Agilent 2100 bioanalyzer by on-chip antibody staining. Agilent Technologies, Application Notes. Agilent, SantaClara, CA.

Govoni, G., and P. Gros. 1998. Macrophage Nramp1 and its role in resistance to microbial infections. Inflamm. Res. 47:277-284.

Guha, M., and N. Mackman. 2001. LPS induction of gene expression in human monocytes. Cell. Signal. 13:85-94.

Huber, M., C. Kalis, S. Keck, Z. Jiang, P. Georgel, X. Du, L. Shamel, S. Sovath, S. Mudd, B. Beutler, C. Galanos, and M. A. Freudenberg. 2006. R-form LPS, the master key to the activation ofTLR4/MD2-positive cells. Eur. J. Immunol. 36:701-711.

Ibeagha-Awemu, E. M., J. W. Lee, A. E. Ibeagha, D. D. Bannerman, M. J. Paape, and X. Zhao. 2008. Bacterial lipopolysaccharide induces increased expression of toll-like receptor (TLR) 4 and downstream TLR signaling molecules in bovine mammary epithelial cells. Vet. Res. 39:11. (Abstr.) 
Joo, Y. S., J. S. Moon, L. K. Fox, G. H. Suh, N. H. Kwon, S. H. Kim, and Y. H. Park. 2003. Comparison of natural resistance-associated macrophage protein (Nramp1) expression between cows with high and low milk somatic cells counts. Asian-australas. J. Anim. Sci. 16:1830-1836.

Lafuse, W. P., G. R. Alvarez, and B. S. Zwilling. 2002. Role of MAP kinase activation in Nramp1 mRNA stability in RAW264.7 macrophages expressing Nramp1 (Gly169). Cell. Immunol. 215:195-206.

Lewkowicz, P., H. Tchorzewski, K. Dyternerska, M. Banasik, and N. Lewkowicz. 2005. Epidermal growth factor enhances TNF- $\alpha-$ induced priming of human neutrophils. Immunol. Lett. 96:203210.

McClenahan, D., J. Fagliari, O. Evanson, and B. S. D. Weiss. 2000. Role of inflammatory mediators in priming, activation, and deformability of bovine neutrophils. Am. J. Vet. Res. 61:492498.

Monfardini, E., M. J. Paape, Y. Wang, A. V. Capuco, M. Husheem, L. Wood, and C. Burvenich. 2002. Evaluation of L-selectin expression and assessment of protein tyrosine phosphorylation in bovine polymorphonuclear neutrophil leukocytes around parturition. Vet. Res. 33:271-281.

Mulero, V., S. Searle, J. M. Blackwell, and J. H. Brock. 2002. Solute carrier 11a1 (Slc11a1; formerly Nramp1) regulates metabolism and release of iron acquired by phagocytic, but not transferrinreceptor-mediated, iron uptake. Biochem. J. 363:89-94.

National Mastitis Council. 1996. Current Concepts of Bovine Mastitis. 4th ed. National Mastitis Council, Arlington, VA.

Nomura, F., S. Akashi, A. Sakao, S. Sato, T. Kawa, M. Matsumoto, K. Nakanishi, M. Kimoto, K. Miyake, K. Takeda, and S. Akira. 2000. Endotoxin tolerance in mouse peritoneal macrophages correlates with down-regulation of surface Toll-like receptor 4 expression. J. Immunol. 164:3476-3479.

Notebaert, S., L. Duchateau, and E. Meyer. 2005. NF-кB inhibition accelerates apoptosis of bovine neutrophils. Vet. Res. 36:229240.

Paape, M. J., E. M. Lilius, P. A. Wiitanen, M. P. Kontio, and R. H. Miller. 1996. Intramammary defense against infections induced by Escherichia coli in cows. Am. J. Vet. Res. 57:477-482.

Paape, M. J., E. J. Sohn, D. D. Bannerman, R. H. Fetterer, E. E. Connor, and R. R. Peters. 2006. Cytokine secretion by bovine polymorphonuclear neutrophils leukocytes (PMN). Page 13 in Proc. 2nd European Veterinary Immunology Workshop Program and Book of Abstracts. Project: Improving Milk Quality by Reducing Mastitis in Dairy Cattle. Paris, France.

Parker, L. C., M. K. B. Whyte, S. K. Dower, and I. Sabroe. 2005. The expression and roles of Toll like receptors in the biology of the human neutrophil. J. Leukoc. Biol. 77:886-892.
Pearl-Yafe, M., I. Fabian, D. Halperin, E. Flatau, S. Werber, and I. Shalit. 2007. Interferon- $\gamma$ and bacterial lipopolysaccharide act synergistically on human neutrophils enhancing interleukin-8, interleukin-1 $\beta$, tumor necrosis factor- $\alpha$ and interleukin-12 P70 secretion and phagocytosis via up regulation of Toll-like receptor-4. Shock 27:226-231.

Ruchaud-Sparagano, M. H., C. A. Ruivenkamp, P. L. Riches, I. R. Poxton, and I. Dransfield. 1998. Differential effects of bacterial lipopolysaccharides upon neutrophil function. FEBS Lett. 430:363-369

Sauter, K. S., M. Brcic, M. Franchini, and T. W. Jungi. 2007. Stable transduction of bovine TLR-4 and bovine MD-2 into LPSnonresponsive cells and soluble CD14 promote the ability to respond to LPS. Vet. Immunol. Immunopathol. 118:92-104.

Shuster, D. E., M. E. Kehrli Jr., and M. G. Stevens. 1993. Cytokine production during endotoxin-induced mastitis in lactating dairy cows. Am. J. Vet. Res. 54:80-85.

Sohn, E. J., M. J. Paape, E. E. Connor, D. D. Bannerman, R. H. Fetterer, and R. R. Peters. 2007. Bacterial lipopolysaccharide stimulates bovine neutrophil production of TNF- $\alpha$, IL-13, IL-12 and IFN- $\gamma$. Vet. Res. 38:809-818.

Sohn, M. J., G. M. Hur, H. S. Byun, and W. G. Kim. 2008 Cyclo(dehydrohistidyl-L-tryptophyl) inhibits nitric oxide production by preventing the dimerization of inducible nitric oxide synthase. Biochem. Pharmacol. 75:923-930.

Van Oostveldt, K., G. M. Tomita, M. J. Paape, A. V. Capuco, and C. Burvenich. 2002. Apoptosis of bovine neutrophils during mastitis experimentally induced with Escherichia coli or endotoxin. Am. J. Vet. Res. 63:448-453.

Vinokurov, M. G., M. M. Yurinskaya, I. R. Prokhorenko, and S. V. Grachev. 2006. Effect of various E. coli LPS chemotypes on apoptosis and activation of human neutrophils. Bull. Exp. Biol. Med. 142:173-175

Wenz, J. R. G. M. Barrington, F. B. Garry, R. P. Ellis, and R. J. Magnuson. 2006. Magnuson, Escherichia coli serotypes, genotypes and virulence genes and clinical coliform mastitis severity. J. Dairy Sci. 89:3408-3412.

Zhang, G., H. Wu, C. R. Ross, J. E. Minton, and F. Blecha. 2000. Cloning of porcine NRAMP1 and its induction by lipopolysaccharide, tumor necrosis factor alpha, and interleukin-1b: Role of CD14 and mitogen-activated protein kinases. Infect. Immun. 68:1086-1093.

Zughaier, S. M., S. M. Zimmer, A. Datta, R. W. Carlson, and D. S. Stephens. 2005. Differential induction of the Toll-like receptor-4 MyD88-depended and independed signaling pathways by endotoxins. Infect. Immun. 73:2940-2950. 